\title{
Are alternative livelihood projects effective at reducing local threats to specified elements of biodiversity and/or improving or maintaining the conservation status of those elements?
}

Dilys Roe ${ }^{1 *}$, Francesca Booker ${ }^{1,2}$, Mike Day ${ }^{1,2}$, Wen Zhou ${ }^{2}$, Sophie Allebone-Webb ${ }^{3}$, Nicholas A. O. Hill ${ }^{3,4}$, Noelle Kumpel ${ }^{3}$, Gillian Petrokofsky²,5, Kent Redford ${ }^{6}$, Diane Russell ${ }^{7}$, Gill Shepherd ${ }^{8}$, Juliet Wright ${ }^{3,9}$ and Terry C. H. Sunderland ${ }^{2}$

\begin{abstract}
Background: Alternative livelihood projects are used by a variety of organisations as a tool for achieving biodiversity conservation. However, despite characterising many conservation approaches, very little is known about what impacts (if any) alternative livelihood projects have had on biodiversity conservation, as well as what determines the relative success or failure of these interventions. Reflecting this concern, Motion 145 was passed at the Vth IUCN World Conservation Congress in 2012 calling for a critical review of alternative livelihood projects and their contribution to biodiversity conservation. This systematic map and review intends to contribute to this critical review and provide an overview for researchers, policy makers and practitioners of the current state of the evidence base.

Methods: Following an a priori protocol, systematic searches for relevant studies were conducted using the bibliographic databases AGRICOLA, AGRIS, CAB Abstracts, Scopus, and Web of Knowledge, as well as internet searches of Google, Google Scholar, and subject specific and institutional websites. In addition, a call for literature was issued among relevant research networks. The titles, abstracts and full texts of the captured studies were assessed using inclusion criteria for the systematic map and the systematic review, respectively. An Excel spreadsheet was used to record data from each study and to provide a systematic map of the evidence for the effectiveness of alternative livelihood studies. The studies that met additional criteria to be included in the systematic review were described in more detail through a narrative synthesis.

Results: Following full text screening, 97 studies were included in the systematic map covering 106 projects using alternative livelihood interventions. Just 22 of these projects met our additional criteria for inclusion in the systematic review, but one project was removed from the detailed narrative synthesis following critical appraisal. The 21 included projects included reports of positive, neutral and negative conservation outcomes.
\end{abstract}

Conclusions: Our results show that there has been an extensive investment in alternative livelihood projects, yet the structure and results of most of these projects have not been documented in a way that they can be captured using standardised search processes. Either this is because there has been little reporting on the outcomes of these projects,

\footnotetext{
*Correspondence: dilys.roe@iied.org

${ }^{1}$ International Institute for Environment and Development (IIED), 80-86

Grays Inn Road, London WC1X 8NH, UK

Full list of author information is available at the end of the article
} 
or that post-project monitoring is largely absent. The implications of this review for policy, management and future research are provided in relation to this evidence gap.

Keywords: Alternative livelihood, Biodiversity, Conservation, Community attitudes, Conservation threats, Systematic map, Systematic review

\section{Background}

"Alternative livelihood" projects have long been used as a strategy for reducing local level threats to species, habitats or resources of conservation concern. For example, the provision of alternative protein and income-generating sources to bushmeat hunters is one of the most widely used strategies aimed at reducing bushmeat consumption and trade by local people [1-3]. Despite the common deployment of these projects, there has been little analysis of their effectiveness [4].

There is no common definition of alternative livelihood projects. In general, however, they can be understood to be an approach to achieving biodiversity conservation by substituting a livelihood strategy that is causing harm to a biodiversity target-for example, through unsustainable use-for one that has a lesser, or negligible, impact on the same target. In some cases this might mean providing an alternative resource to the one that is being exploited. An example is encouraging local people to farm cane rats as a source of protein rather than hunting bushmeat [1]. In other cases, the focus of a project might be providing an alternative occupation or source of income. Examples include craft making [5] or beekeeping [6] as substitutes for expanding subsistence agriculture around protected areas, or seaweed farming as an alternative to artisanal fishing $[7,8]$.

A third approach involves encouraging an alternative method of exploiting a resource that has a lower impact than the original method. Examples of such interventions include the promotion of fuel-efficient stoves to reduce the demand for firewood [9]; or the introduction of a mariculture programme to ameliorate pressure on a certain fish species [10]. Alternative livelihood projects are sometimes stand-alone initiatives and at other times part of a broader integrated conservation and development (ICD) programme. In all cases, the alternative livelihood initiatives share a common objective: to provide local people with an alternative means of making a living that reduces pressure on a particular element of biodiversity.

Both conservation and development practitioners have expressed concern that the alternative livelihood approach may be flawed $[11,12]$. In particular, since the emergence of the sustainable livelihoods framework in the late 1990s [13], it is recognised that natural resource dependent households typically engage in multiple and diverse livelihood activities. As such, a newly introduced alternative livelihood may simply be incorporated into the overall mix of livelihood activities, rather than acting as a replacement for an existing activity [14].

At the Vth IUCN World Conservation Congress in 2012, a motion was passed calling for a critical review of the biodiversity benefits of alternative livelihood projects [15]. The motion was driven by the understanding that such projects attract significant amounts of donor funding but, in the absence of evidence of their effectiveness, represent a potentially wasted investment in conservation. Examples of the on-going donor commitment to alternative livelihood projects include the Central African Regional Program for the Environment (CARPE) funded by the United States Agency for International Development (USAID), the current (2012-2020) phase of which includes an objective to "expand alternative livelihood opportunities for rural communities" [16]. In Sierra Leone, following the Ebola crisis, the United Nations Development Programme (UNDP) has launched a project to tackle the bushmeat trade "by offering safe, sustainable alternatives" in an attempt to "reduce the risks of future pandemics, protect livelihoods and address environmental concerns" [17].

This study intends to contribute to the critical review of the biodiversity benefits of alternative livelihood projects, as called for by the IUCN motion. Specifically, it (1) describes the volume and nature of evidence on the effectiveness of alternative livelihood projects and the prevailing evidence gaps (the systematic map); and, (2) synthesises the findings of empirical studies that evaluate conservation effectiveness (the systematic review). This study complements and expands upon a recent review of alternative livelihood projects focussed specifically at reducing bushmeat hunting in Central Africa [4]. That review described the characteristics of 15 projects but found that only three monitored any change in hunting behaviour and only one went on to look at subsequent ecological impacts. In this study we similarly consider project effectiveness on the basis of conservation rather than livelihoods outcomes.

Following an initial stakeholder meeting held in July 2013 with practitioners and researchers from the International Institute for Environment and Development, the Zoological Society of London, the Centre for International Forestry Research, and the University of Oxford, 
the group framed its primary research question for the systematic review as follows: "Are alternative livelihood projects effective at reducing local threats to specified elements of biodiversity and/or improving or maintaining the conservation status of those elements?" A secondary research question-addressed by the systematic map-posits: "What is the state of the evidence base on the effectiveness of alternative livelihood projects for biodiversity conservation?"

Within these research questions we define alternative livelihood projects as interventions that seek to alleviate a human threat to biodiversity through providing, or encouraging the use of, an alternative resource; an alternative occupation; or an alternative (lower impact) method of exploitation. Our definition distinguishes the scope of our study from those projects that have a broader focus on livelihoods, which may encompass any conservation intervention that seeks to engage local people-for example community-based conservation, payments for ecosystem service (PES) schemes and integrated conservation and development programmes [18]. We include such approaches in our study only if they have used an alternative livelihood intervention as a component of their initiative. Specifically, our definition focusses on the term 'alternative' and implies that there is some kind of substitution of an activity, or behaviour, which poses a threat to a specified biodiversity target for one that does not pose a threat (or at least poses less of a threat).

We define effectiveness as a reduction in the threat to the specified biodiversity target as evidenced by a change in human attitude, or behaviour, or ultimately by an improvement in the conservation status of the specified element of biodiversity. We recognise that there is no universal direct causal link between changes in attitudes, changes in behaviour and changes in conservation status. However, a theory of change developed by the conservation organisation RARE highlights behaviour change as a key pre-requisite for reducing threats to conservation and therefore improving the conservation status of the biodiversity target, and attitude change as a key step in bringing about behaviour change [19].

Table 1 summarises the different population, intervention, comparator, and outcome (PICO) components of our primary research question.

\section{Methods}

An a priori systematic review protocol [20] describes our methods in detail. A summary is presented here, and highlights small amendments that we made when undertaking the review.

\section{Searches}

\section{Search terms and languages}

Initial literature searching was tested in Scopus [21] and Web of Knowledge [22]. Search terms included synonyms for alternative livelihood, examples of specific types of alternative livelihood interventions (such as beekeeping or cane rat farming) and terms related to biodiversity or conservation. A scoping search was also conducted in CAB Abstracts [23] to help to refine, and add, search terms. Final search terms were selected based on the number of search results they generated and the inclusion of publications from a test library of 15 relevant studies. The full set of search terms is detailed in Additional file 1. Searches were conducted in English and then replicated in French for grey literature searching where time permitted (this was not necessary for bibliographic database searches as titles and abstracts for all foreign language papers are included in English in the selected databases).

\section{Searches}

We searched the online bibliographic databases Scopus [21], Web of Knowledge [22], CAB Abstracts [23], AGRIS [24] and AGRICOLA [25] for relevant publications. The strategy varied slightly between the different databases according to their particular use of Boolean operators, wildcards, proximity searches and the exclusion of irrelevant subject areas. Full descriptions of the final search strategies are provided in Additional file 2.

In addition to the bibliographic databases, we also searched a number of individual journals. Searches were conducted in English only due to time limitations. We used simple search terms and strings such as 'livelihood and conservation' to search two regional journal platforms-African Journals Online [26] and Asian Journals Online [27] - and the Directory of Open Access Journals (DOAJ) [28], capturing the first 200 results in each case. We also checked the journals covered by the Poverty and Conservation Learning Group (PCLG) journal digest [29] on a monthly basis from February 2015 until April 2015.

Table 1 Elements of the systematic review question

\begin{tabular}{llcl}
\hline Population & Intervention & Comparators & Outcomes \\
\hline $\begin{array}{l}\text { Biodiversity } \\
\text { target }\end{array}$ & $\begin{array}{c}\text { Alternative livelihood } \\
\text { project }\end{array}$ & $\begin{array}{c}\text { Prior to alternative livelihood project interven- } \\
\text { tion/without alternative livelihood interven- } \\
\text { tion }\end{array}$ & $\begin{array}{c}\text { Change in threat and/or conservation } \\
\text { status of specified biodiversity target }\end{array}$ \\
\hline
\end{tabular}


A full list of the journals that were checked is provided in Additional file 3.

We conducted internet searches using Google [30] and Google Scholar [31]. For Google Scholar we used 14 short search strings in both English and French. The first 150 results were captured for six strings that were based on synonyms for alternative livelihood, and the first 100 results were captured for the remaining eight strings that included terms for specific types of alternative livelihood interventions. We also used simple search terms in Google to search for additional web-based material, capturing the first 100 results in each case. Google searches were conducted in English only due to time restrictions. The search strings for Google Scholar and Google are listed in Additional file 4.

We used simple search terms to search five thesis databases-DART-Europe E Thesis [32], Ethos [33], National ETD Portal South Africa [34], Open Access Theses and Dissertations [35] and ProQuest Digital Dissertations and Theses [36] - capturing the first 200 results in each case. Searches were conducted in English only, as we did not have the time to search the French Language thesis repository Systeme Universitaire de Documentation [37] (as proposed in our protocol).

We searched for grey literature by targeting the websites of key donor, implementer and research organisations-selected according to their prominence in conservation and development, as well as the existence of searchable websites. A number of subject specific websites with potentially relevant publications were also searched. Searches on these websites used simple search terms including: 'conservation AND development' or just 'alternative livelihood' where characters were limited. Table 2 provides details of the websites that we included. Searches were conducted in English only due to time limitations.

\section{Stakeholder engagement}

In addition to the web-based literature searches, we sought expert advice on relevant studies through a process of stakeholder engagement. We produced a project flyer in English and French that we disseminated through the websites of the review team's host institutions and at various conferences and workshops attended by team

Table 2 Websites searched as part of the specialist searches

\begin{tabular}{|c|c|}
\hline Organisation & Website \\
\hline African Development Bank & http://www.afdb.org/en/search/ \\
\hline Asian Development Bank & http://adb.org/projects/search \\
\hline Birdlife International & http://www.birdlife.org/search \\
\hline Center for International Forestry Research & http://www.cifor.org/ \\
\hline CGIAR & http://www.cgiar.org \\
\hline Conservation International & http://www.conservation.org/Pages/default.aspx \\
\hline Convention on Biological Diversity & https://www.cbd.int/kb/ \\
\hline Critical Ecosystem Partnership Fund & http://www.cepf.net/Pages/default.aspx \\
\hline DAI & http://ec.europa.eu/index_en.htm \\
\hline Department for International Development-Research for Development & http://r4d.dfid.gov.uk/ \\
\hline European Commission & http://ec.europa.eu/index_en.htm \\
\hline Fauna and Flora International & http://www.fauna-flora.org/ \\
\hline Global Environment Facility & http://www.thegef.org/gef/search/node/ \\
\hline Inter-American Development Bank & http://www.iadb.org/en/inter-american-development-bank,2837.html \\
\hline International Fund for Agricultural Development & http://www.ffad.org/search.htm \\
\hline International Institute for Sustainable Development & http://www.iisd.org/search/ \\
\hline International Union for the Conservation of Nature & http://www.iucn.org/ \\
\hline The Nature Conservancy & http://www.nature.org/ \\
\hline Wildlife Conservation Society & http://www.wcs.org/ \\
\hline World Bank & http://search.worldbank.org/research \\
\hline World Fish & http://www.worldfishcenter.org/search/site \\
\hline WWF International & http://wwf.panda.org/about_our_earth/all_publications/ \\
\hline \multicolumn{2}{|l|}{ Specialist Groups } \\
\hline Conservation Evidence & http://www.conservationevidence.com \\
\hline Eldis & http://www.eldis.org \\
\hline Iliss Africa & http://www.ilissafrica.de/en/ \\
\hline
\end{tabular}


members. We issued a call for case studies in English to key mailing lists, including the Poverty and Conservation Learning Group [38] and Biodiversity-L [39], and produced a blog [40] hosted on the CIFOR and IIED websites. We also made a presentation to the UK Bushmeat Working Group [41] in December 2013. These efforts garnered many publications that were not captured in our electronic searches, including 52 internal publications shared by USAID and six final donor reports from the UK Government's Darwin Initiative. Finally, we formed an advisory group to help guide the study and to provide feedback at different stages of the review process.

\section{Estimating the comprehensiveness of the search}

Although our protocol stated our intention to conduct searches in Spanish, we were unable to do so due to time and resource constraints. As such, some key literature may be missing from our search results. Another possible limitation to the comprehensiveness of our search was the lack of standard terminology for alternative livelihood projects. Not all alternative livelihood projects refer to themselves as such, with variations including 'alternative incomes' or 'alternative occupations,' as well as a wide range of other descriptors such as 'community-based natural resource management', 'enterprise approaches', 'income-generating activities', and 'integrated conservation and development'. Thus, it is possible that our search did not capture all the variations in terminology used to refer to an alternative livelihood project. However, the iterative development of search terms and the incorporation of a wide range of alternative livelihood synonyms in our search strings should have minimised any omissions.

\section{Inclusion criteria}

The primary inclusion criteria for studies to be considered for the systematic map were:

1. Relevant population: the study described the impact on a biodiversity target (for example a protected area, a forest, a particular threatened species). As such, we excluded studies that only described socioeconomic outcomes of alternative livelihood projects.

2. Relevant intervention: the study described an intervention that met our definition of an alternative livelihood project. Accordingly, we excluded studies of projects that adopted a broader focus on livelihoods improvements and where there was no explicit substitution of unsustainable activities.

3. Relevant comparator: the study compared the situation with that prior to the alternative livelihood intervention or to a control without an alternative livelihood intervention.
For studies to be included in the systematic review, they also had to meet an additional criterion:

4. Relevant outcomes: the study assessed the effectiveness of the alternative livelihood project in achieving biodiversity conservation outcomes (including improvements in local attitudes towards conservation, improvements in environmentally damaging behaviour, and improvements in conservation status of the biodiversity target). Thus we excluded studies that did not include an assessment of effectiveness, or that only assessed effectiveness from the perspective of a change in livelihood strategies without consideration of conservation outcomes, or that examined broader projects without disaggregated analysis of the effectiveness of the alternative livelihood component.

A Kappa analysis was performed to ensure that there was a high level of agreement between the five researchers applying the inclusion criteria. This process was repeated three times, first on a random sample of 200 titles and abstracts and subsequently on a random sample of 100 titles and abstracts, until a Kappa coefficient of above 0.6 was achieved (the level at which agreement between researchers is considered to be substantial). Following this, the five researchers were assigned a portion of the captured studies to independently assess for inclusion. Where there was doubt, each researcher queried the inclusion of a document with the other team members during scheduled meetings. Additional file 5 details the studies that were excluded during full text screening and the reasons for exclusion.

\section{Data extraction}

For studies that met our primary inclusion criteria for the systematic map, descriptive information on the alternative livelihood project-such as the geographical location and the type of approach used-was recorded. For studies that met our additional inclusion criteria for the systematic review, the effectiveness of the alternative livelihood projects for achieving biodiversity conservation outcomes was likewise recorded, including the means by which effectiveness was assessed and the outcomes of this assessment.

We created an Excel spreadsheet to capture data and divided this into a number of different sections according to the type of information captured. The project team presented the data extraction questions featured in the spreadsheet to expert members of the UK Bushmeat Working Group at their December 2013 meeting in London, which provided useful feedback to refine the data extraction strategy. The spreadsheet was also tested using studies from the test library with the reviewers 
comparing and discussing what information to extract in each section in order to achieve a shared understanding across the team. The Excel spreadsheet used for data extraction is provided in Additional file 6 and details the full list of questions along with the data extracted for each study included in the systematic map and review.

\section{Potential effect modifiers and reasons for heterogeneity}

Data on potential effect modifiers were extracted from studies including: the presence of a contractual agreement; local design of the project; the project's dependence on conservation outcomes; and the specific targeting of individuals or groups causing the biodiversity threat.

\section{Critical appraisal}

Studies that were included in the systematic review were subject to a process of critical appraisal using six criteria formulated in consultation with our advisory group and published in our protocol (Table 3). From the outset, the review team and advisory board were aware that we would be unable to directly apply an established critical appraisal tool such as the Cochrane Collaboration Risk of Bias [42] due to the heterogeneous nature of the literature and the fact that much of it is predominantly descriptive rather than evaluative. Instead, the review team devised an adaptation of the 'Quality Assessment Tool for Quantitative Studies (QATQS)' [43] to allow for critical appraisal criteria that could qualitatively assess quantitative studies. Adherence to the criteria was assessed for each study, and studies were excluded from the systematic review where they did not meet at least one of the criteria. In each case the assessment was carried out by two researchers who discussed any differences in opinion on each individual study until consensus was reached on the scores. Studies were then ranked as strong reliability (meets all six criteria), moderate reliability (meets four or five criteria) or weak reliability (meets one to three criteria). The term 'reliable' is used in the sense of 'low risk of bias' following the categories in QATQS. The assessment was conducted by three of the review team through discussions together on the presence of absence of the criteria in each of the studies.

In our protocol we had proposed using the additional assessment criterion that the methodology allows for causal links to be established. This proved difficult to assess and was omitted following examination of the studies and discussion amongst the review team.

\section{Data synthesis}

Descriptive statistics were used to analyse the overall body of evidence and synthesise project characteristics, including location, type of intervention, biodiversity targets, and other parameters as detailed in the results section below. For those studies included in the systematic review, we used narrative synthesis to explore the different biodiversity conservation outcomes (positive, neutral, or negative) of the alternative livelihood projects. As predicted in our protocol, we were not able to undertake a meta-analysis of the evidence due to the limited number, and heterogeneous nature, of projects that were included in the review.

\section{Results}

\section{Number and types of studies}

The main literature search was conducted between February and April 2014. The literature search returned 22,146 studies $(17,675$ from bibliographic databases and

\section{Table 3 Critical appraisal criteria}

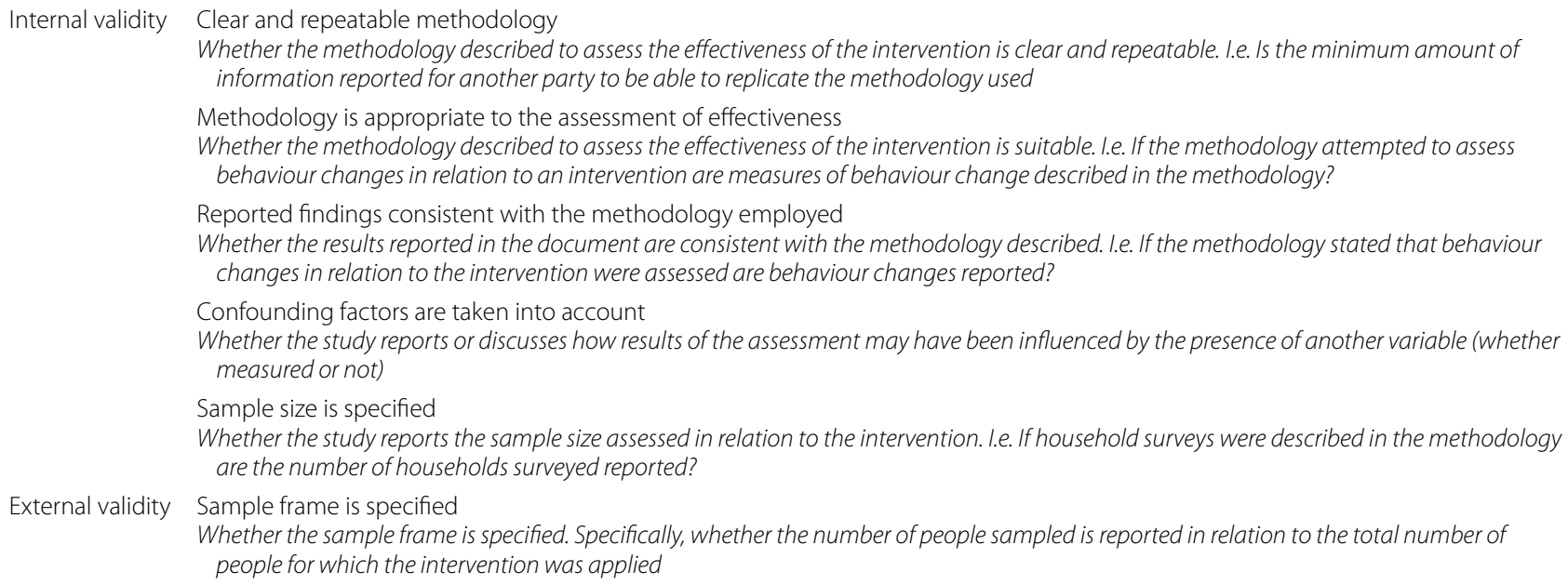


4471 from grey literature searches). A limited number of these (185) were screened by title and abstract at the same time due to downloading issues, while the remainder were screened first by title and then by abstract. A total of 839 studies were included for full text screening of which 97 met our criteria for the systematic map and 21 of these met our additional criteria for inclusion in the systematic review. Figure 1 summarises the document screening process, while Table 4 illustrates the distribution of document types included in the systematic map and review. Of the 22, 146 studies captured, 82 $(0.3 \%)$ could not be found as full texts and were subsequently removed from the systematic map and review. These studies are listed in Additional file 5.

We placed no date restrictions on our search and the studies retrieved were published between 1993 and 2015. The majority of studies were published in the last 10 years, with only one published prior to 2000 (Fig. 2).

Stage 1 screening
Citations identified that suit
immediate screening (not easily
downloadable e.g. project reports or
large theses).
Grey literature searching $=185$
(full text unavailable 12)

Full text screening

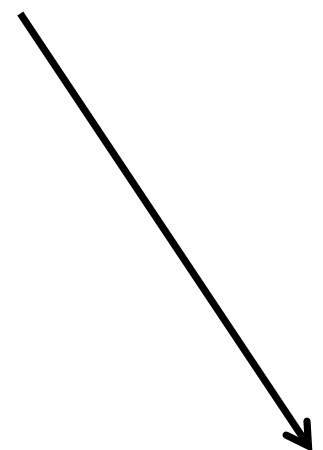

Stage 2 screening

Citations captured through electronic

searches e.g. online databases

Bibliographic databases $=17675$

Grey literature searching $=4286$

Title and abstract screening

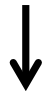

Bibliographic databases $=598$

(full text unavailable 49)

Grey literature searching $=241$

(full text unavailable 33)

Full text screening

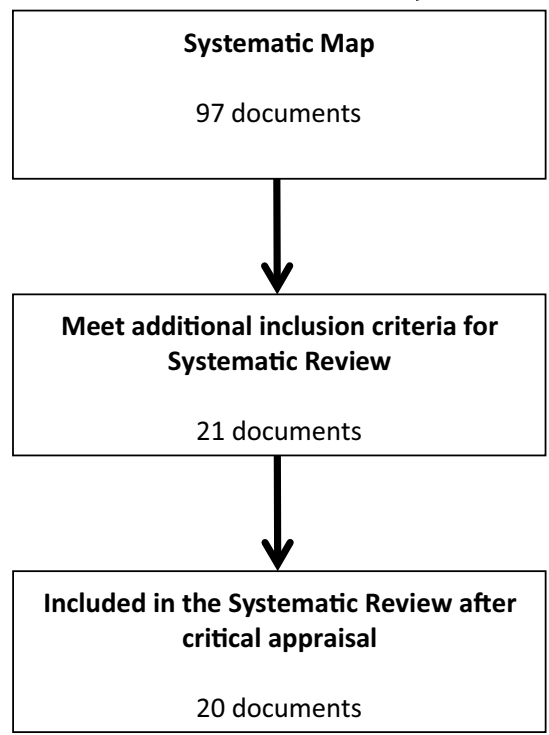

Fig. 1 Number of studies retrieved in the search and passing each stage of relevance assessment 
Table 4 The source of studies included in systematic map and review (number in brackets indicates studies meeting the criteria to be included in the systematic review)

\begin{tabular}{lll}
\hline Source & $\begin{array}{l}\text { Bibliographic } \\
\text { databases }\end{array}$ & $\begin{array}{l}\text { Grey literature } \\
\text { searches }\end{array}$ \\
\hline Journal article & $41(10)$ & $18(7)$ \\
Book chapter & 3 & 0 \\
Thesis & 0 & $5(3)$ \\
Report & 0 & $26(1)$ \\
Miscellaneous & 1 & 1 \\
Working paper & 1 & 0 \\
Conference proceedings & 0 & 1 \\
\hline
\end{tabular}

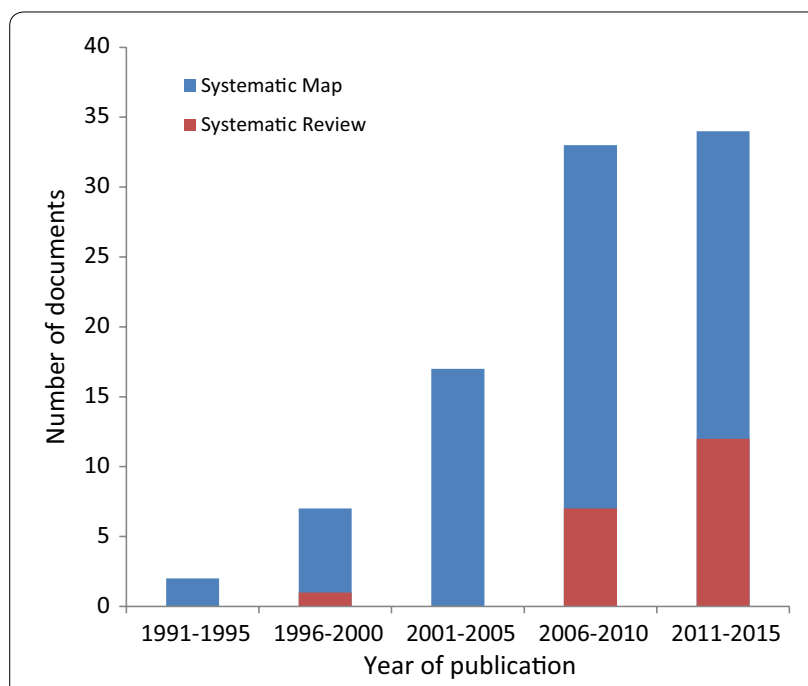

Fig. 2 Publication year of studies included for the map and review. N.B. Four studies did not specify the year of publication

\section{Mapping the nature and state of evidence}

This section of our results addresses our secondary research question: "What is the state of the evidence base on the effectiveness of alternative livelihood projects for biodiversity conservation?" Here, we first provide some broad findings as to the characteristics of the projects and specific alternative livelihood interventions that have been described in the studies which we retrieved from our search. We then provide an assessment of the state of the evidence base highlighting the key evidence gaps (the systematic map). The subsequent section of results synthesises the findings of the sub-set of studies that met our criteria for inclusion in the systematic review.

The 97 studies included in the systematic map describe a total of 106 alternative livelihood projects-these are listed in Additional file 7 . Nine projects were studied more than once; and eight studies covered more than one project.

\section{Geographical location of projects}

The projects identified in the studies were widely dispersed, with the vast majority located in developing countries. $44 \%$ of all projects were located in Asia and $32 \%$ of all projects were located in Africa with only one project in Europe (Greece). India hosted the largest number of projects (14\%) of any individual country, followed by Indonesia and Tanzania (7 \% each). Figure 3 summarises the geographical distribution of the projects (although we recognise this distribution is biased by our inclusion of studies in French and English only), and Fig. 4 lists the number of projects in individual countries.

\section{Ecological distribution of projects}

All the projects were categorised according to the habitat type in which they were implemented using the Birdlife International classification of habitats [44]. The projects fell into only four broad habitat types: marine (which comprises the Birdlife categories of sea and coastline); forests; savannah; and wetlands (including freshwater lakes). The majority ( $n=69,65 \%$ ) of projects were implemented in forest habitats (Fig. 5). The data did not reveal any correlation between the type of habitat and the geographic location of projects, nor between the type of habitat and the type of project.

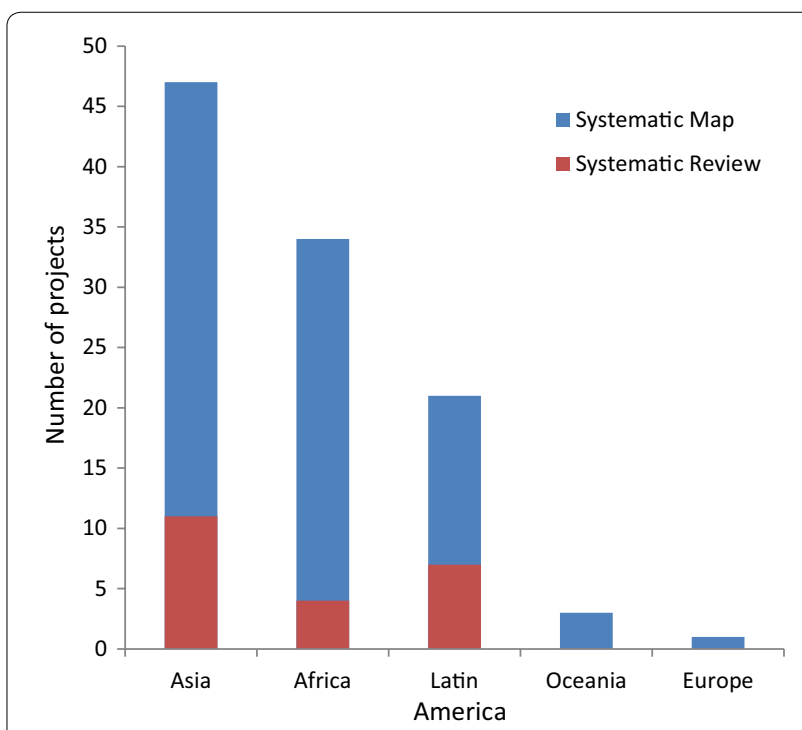

Fig. 3 Geographic location of projects included within the systematic map and the review 


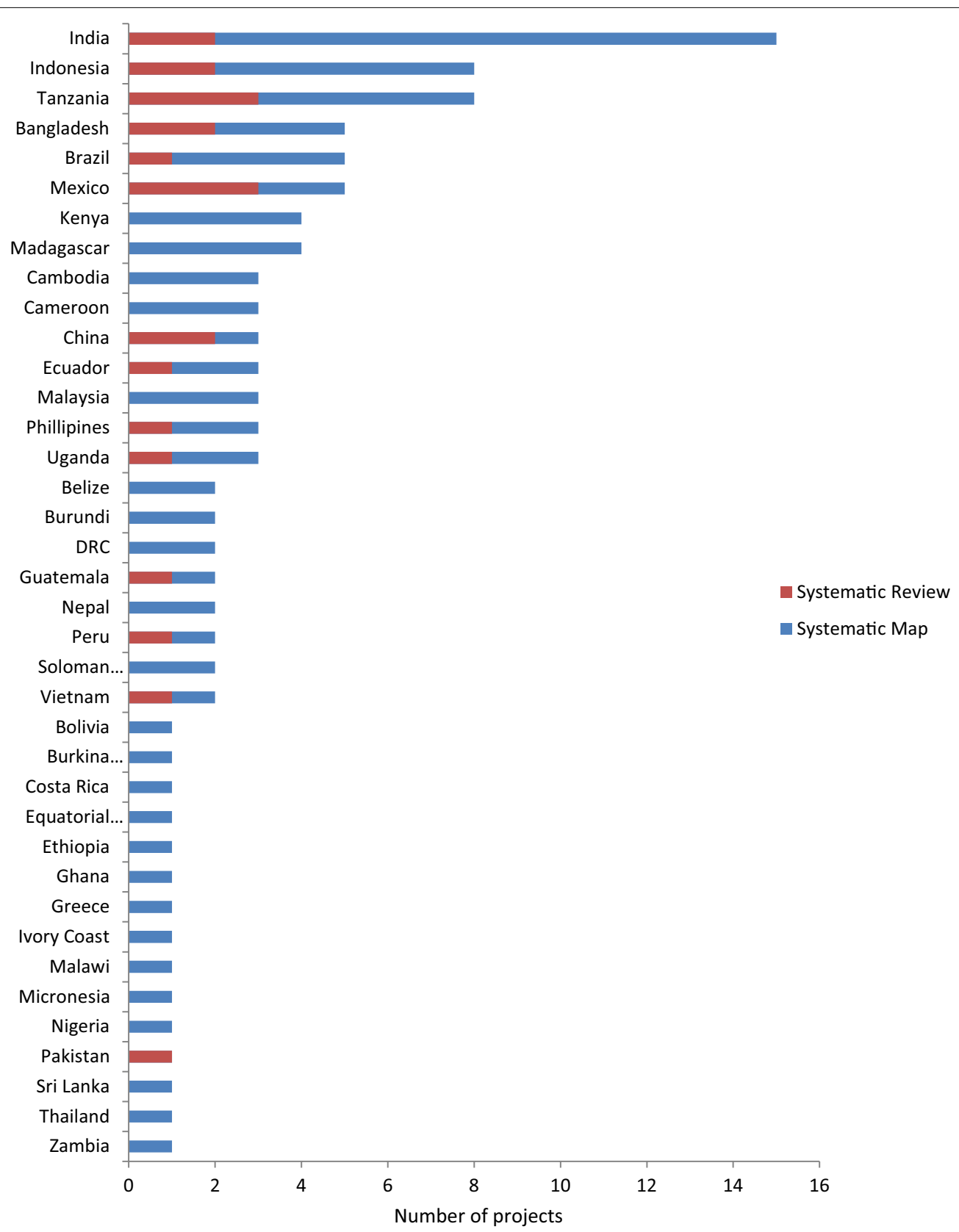

Fig. 4 Number of alternative livelihood projects by country included in the systematic map and systematic review

\section{Types of alternative livelihood interventions used} in projects

The 106 projects captured by the systematic map included examples of all three types of alternative livelihood interventions: alternative resource, alternative occupation, and alternative method of exploitation. Some projects used different combinations of interventions while others used only one. By far the most common type of intervention was the provision of alternative occupation(s). Those projects that used more than one alternative livelihood intervention most commonly combined an alternative occupation with another intervention type. Table 5 describes the number of projects that employed each type of intervention.

The specific strategies used by projects were diverse within each of these alternative livelihood intervention types. Under the category of alternative method(s), one of the most common interventions was the introduction 


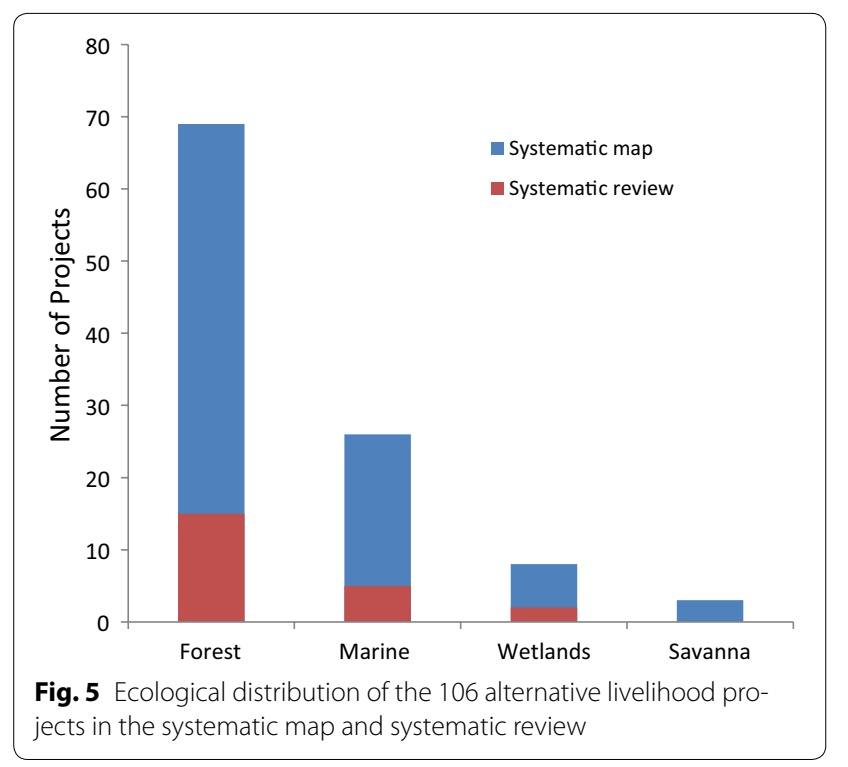

of fuel-efficient stoves to reduce fuelwood use and its impact on forest resources. Other approaches included the introduction of non-lethal resource harvesting methods, enhancing the efficiency of existing harvesting methods and reducing the exploitation of wild resources (for example, using oyster beds instead of wild capture), and intensifying agricultural production to reduce land expansion in ecologically sensitive areas.

Among those interventions providing an alternative resource(s), a common approach was the introduction of stoves that use liquefied petroleum gas (LPG) or kerosene as an alternative energy source to wood fuel. Other common interventions included the planting and use of trees on farms and/or village lands as an alternative resource to trees within conservation sites, and rearing of domestic animals to substitute for wild species targeted by bushmeat hunting.

Alternative occupation interventions were diverse, and included the cultivation and commercialisation of nontimber forest products (NTFP), beekeeping, tourism, handicraft production, livestock rearing and horticultural activities. Less common occupations included tailoring and barbering, rickshaw pulling and bicycle repairing. In some cases, alternative occupations were introduced in the form of employment opportunities and in other cases, enterprise opportunities.

The projects varied according to their linkage with conservation outcomes. Altogether, 62 of the 106 projects $(58 \%)$ had at least one intervention whose success was dependent on successful conservation. Examples of

Table 5 The number of projects using different types of alternative livelihood interventions

\begin{tabular}{|c|c|c|c|}
\hline Types of intervention combinations & Map & Review & Project examples \\
\hline Alternative occupation only & 73 & 15 & $\begin{array}{l}\text { Network of Locally Managed Marine Protected Areas, Solomon Islands } \\
\text { Alternative occupation: thee establishment of alternative income generating projects } \\
\text { including beekeeping, ecotourism, clam and coral farming and coconut oil press }\end{array}$ \\
\hline Alternative resource only & 8 & 2 & $\begin{array}{l}\text { Turtle conservation, Indonesia } \\
\text { Alternative resource: Introduction of pig breeding as a replacement for turtle meat }\end{array}$ \\
\hline Alternative methods only & 9 & 4 & $\begin{array}{l}\text { The ProNaturaleza Project, Peru } \\
\text { Alternative method: Introduction of new method to sustainably harvest fruits by } \\
\text { climbing, rather than felling Moriche palms }\end{array}$ \\
\hline Alternative occupation + alternative resource & 9 & 1 & $\begin{array}{l}\text { Terai Arc Landscape, Nepal } \\
\text { Alternative occupation: Promotion of alternative income generating activities through } \\
\text { micro-credit schemes } \\
\text { Alternative resource: Adoption of alternative energy such as biogas, improved cook } \\
\text { stoves, bio-briquette }\end{array}$ \\
\hline Alternative occupation + Alternative methods & 1 & 0 & $\begin{array}{l}\text { Mananara Project, Madagascar } \\
\text { Alternative occupation: Introduction of animal rearing and beekeeping } \\
\text { Alternative method: Introduction of alternative fishing methods }\end{array}$ \\
\hline Alternative resource + Alternative methods & 2 & 0 & $\begin{array}{l}\text { CARE Fishing Villages Project, Uganda } \\
\text { Alternative resource: Planting woodlots which can then be harvested to offset wood } \\
\text { demand from within the park } \\
\text { Alternative method: Fish smoking kilns to reduce demands for firewood }\end{array}$ \\
\hline All three interventions & 4 & 0 & $\begin{array}{l}\text { India Ecodevelopment Project-Buza Tiger Reserve } \\
\text { Alternative occupation: Promotion of income augmenting alternatives (e.g. bamboo } \\
\text { weaving, poultry, pig and goat rearing, loans for training to support self-employ- } \\
\text { ment initiatives such as tailoring, sale of horticulture-vegetable or other minor forest } \\
\text { products) } \\
\text { Alternative resource: Plantation of fast growing fuelwood species outside the } \\
\text { protected area, Alternative method: distribution of smokeless stoves to village com- } \\
\text { munities }\end{array}$ \\
\hline
\end{tabular}


such interventions include the alternative occupations of ecotourism, beekeeping, butterfly farming-conservation being critical for ensuring these enterprises remain viable. The other 29 projects $(27 \%)$ were not dependent on conservation and included interventions such as the alternative occupation of becoming a barber or a tailor, use of non-fuelwood energy sources, and alternative methods to increase agricultural productivity. In 15 projects (14\%), the dependence on conservation activities was either not clear or not specified.

Only a few (9.8 \%) projects had any kind of contractual agreement to secure conservation outcomes. Where these were used they were based on: sanctioning noncompliance with conservation regulations; requiring beneficiaries agree to specified conservation behaviours; awarding loans only to those activities that were deemed to have no negative environmental impact; requiring participants to hand-in guns or wire snares; and providing alternative livelihood opportunities in exchange for labour needed for sustainable forest management.

A larger number of the projects (88 of 106 projects) were introduced as part of a wider initiative such as an integrated conservation and development (ICD) programme, rather than as stand-alone projects. Such programmes often had multiple components in addition to alternative livelihood interventions, such as sustainable management/user restrictions (66 projects); environmental education and awareness raising (45 projects); other livelihood interventions (44 projects); law enforcement (15 projects); governance and capacity building (14 projects); health improvements (7 projects); and ecological restoration (6 projects).

\section{Start date, duration and scale of projects}

The majority of projects were initiated before 2004 (Fig. 6). Very limited information was provided on the duration or scale of the projects, and for the projects that were part of wider programmes, information was particularly scarce. For the 18 stand-alone projects details on scale (in terms of participation) were provided for just 12 projects and varied from 14 to 28 individual farmers or boat-owners, to seven communities. Little information was provided on projects' duration or budget. For five of the projects the duration was recorded (ranging from 2 to 10 years) and for two projects the budget was recorded (in each case falling into our category of a medium-sized project (US \$10,000-100,000).

\section{Types of biodiversity target}

The projects were focussed on a range of different biodiversity targets (Fig. 7). The most common $(n=67,63 \%)$ was a protected area, while 23 projects (22\%) targeted other sites of conservation interest such as coral reefs

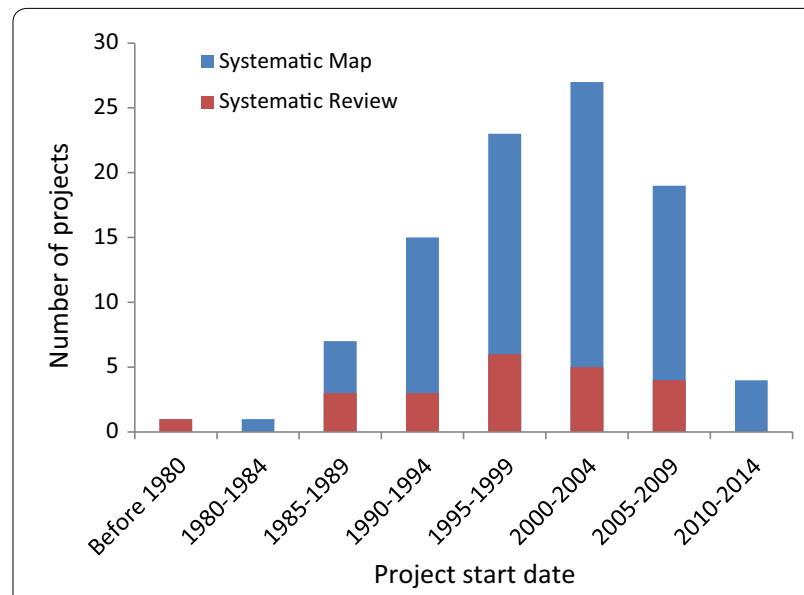

Fig. 6 Start date of projects included for the map and review. N.B 10 projects did not specify a project start date

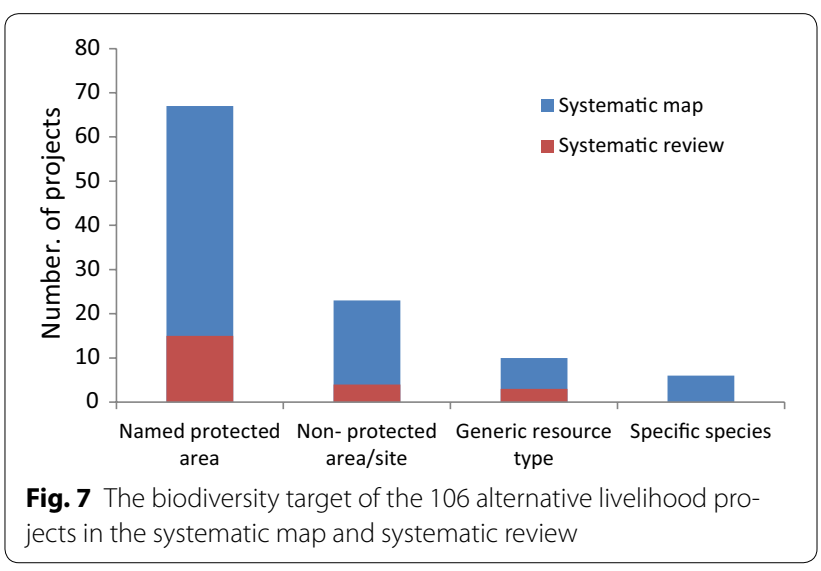

or forests. Ten projects (9\%) aimed to protect a particular types of resource such as fish, and six projects (6\%) aimed to protect a particular species (five of which targeted marine turtle species).

\section{Types of target participants}

All of the projects (aside from two where details were not provided) identified local people as being a threat to biodiversity conservation. In $30(28 \%)$ of the projects a specific group such as hunters, poachers, farmers, or fishers were targeted. For 40 of the projects (38\%), the wider community was the target, i.e. park/reserve adjacent communities. Some 36 projects (34\%) did not specify a target group while 18 projects (17 \%) targeted additional groups beyond those identified as posing a threat to biodiversity (including women, indigenous peoples, young people, and poor or otherwise marginalised community members).

Very little information was provided as to whether any of these target participants had been involved in the 
design of the alternative livelihood interventions. In some cases, projects were described as 'participatory', but with little qualification as to what this actually entailed. In only nine $(8 \%)$ projects there was a clear statement that there had been some form of local involvement in the design of interventions. This was through consultation or participatory rural appraisal methods to gather information on what types of alternative livelihood interventions would be of interest.

\section{Types of threats addressed}

The 106 projects identified were used to address a wide variety of threats to biodiversity. The main threats can be categorised as agriculture, extraction of forest resources, hunting and trapping of wildlife, and fishing. Many of the alternative livelihood interventions were used to address a mixture of different threats in one site rather than targeting one specific threat. A particularly common threat (identified as a threat in 49 of the 106 projects included in the map) was illegal or unsustainable extraction of forest resources (including timber, fuelwood, fodder, poles and other NTFPs) and associated forest degradation.

We categorised hunting separately from the extraction of forest resources as this included both forest and non-forest wildlife. In total, 38 projects (36 \%) included hunting or trapping as one of the threats that they were attempting to address. It was often difficult to determine from the studies if hunting was for immediate consumption or trade or both, and whether it was for meat alone or for other commodities (e.g. pangolin scales and other body parts). Concerns regarding agriculture featured in 48 projects $(45 \%)$ and included so-called "slash and burn" agriculture; agricultural expansion and associated land conversion; and livestock grazing. Another 27 projects $(25 \%)$ identified unsustainable fishing as a key threat either as a result of fishing pressure or the use of destructive methods (such as the use of chemicals or dynamite). Less frequently mentioned threats included human-wildlife conflict, artisanal mining, local hostility to conservation and cultivation of narcotic plants.

Table 6 summarises the threats that were most commonly associated with different biodiversity targets. It was not possible to explore if there was any potential correlation between the type of alternative livelihood intervention used and the type of threat addressed, as many projects address a broad mix of threats and there appears to be limited targeting.

\section{Conservation outcomes}

Altogether 106 projects were captured by our search, but just $22 \mathrm{had}$ an assessment of conservation effectiveness. Of the remaining 84 projects, 21 were part of wider initiatives where there was an assessment of conservation
Table 6 Numbers of projects identifying different types of threat towards different types of biodiversity target

\begin{tabular}{lllll}
\hline & Agriculture & $\begin{array}{l}\text { Forest } \\
\text { resource } \\
\text { extraction }\end{array}$ & $\begin{array}{l}\text { Hunting } \\
\text { and } \\
\text { trapping }\end{array}$ & $\begin{array}{l}\text { Unsustain- } \\
\text { able fishing }\end{array}$ \\
\hline $\begin{array}{l}\text { Protected } \\
\text { area }\end{array}$ & 34 & 38 & 26 & 12 \\
$\begin{array}{l}\text { Non- } \\
\text { protected } \\
\text { site } \\
\begin{array}{c}\text { Generic } \\
\text { resource } \\
\text { type }\end{array}\end{array}$ & 14 & 9 & 6 & 7 \\
$\begin{array}{c}\text { Particular } \\
\text { species/ }\end{array}$ & 0 & 2 & 1 & 7 \\
taxa & 0 & 5 & 1 \\
\hline
\end{tabular}

effectiveness, but this was not disaggregated for the alternative livelihoods intervention(s). The final 63 projects were not studied for conservation effectiveness at all.

Of the 22 projects where there was a measure of conservation effectiveness, one was discarded since the study of its effectiveness did not meet any of our critical appraisal criteria were met. Of the remaining 21 projects, nine were reported as having been effective (positive conservation outcome), nine were reported as being neutral (no change) and three had a negative conservation outcome. These are discussed in more detail in the systematic review results below. Figure 8 provides a "heat map" to illustrate the weight of evidence for the different outcomes of different types of alternative livelihoods interventions (note the numbers do not add up to our total of 97 studies or 106 projects as in some cases there are multiple studies for one project, and in other case multiple projects are covered by one study).

\section{Narrative synthesis}

In this section we report on the findings of studies that met our additional criteria for the systematic review, i.e. those studies for which there was a clear assessment of the effectiveness of alternative livelihood intervention(s) for achieving biodiversity conservation outcomes. A total of 21 studies detailing 22 projects met this inclusion criteria and were subject to critical appraisal. Of these, six studies ranked as strong reliability (meeting all six critical appraisal criteria), ten studies ranked as moderate reliability (meeting four or five criteria), and four studies ranked as weak reliability (meeting one or two criteria). We excluded one study after critical appraisal as it met none of appraisal criteria. Those studies that scored medium and low reliability commonly did not report details on the critical appraisal criteria pertaining to sample frame and confounding variables. Additional file 8 provides full details of studies' critical appraisal values. 


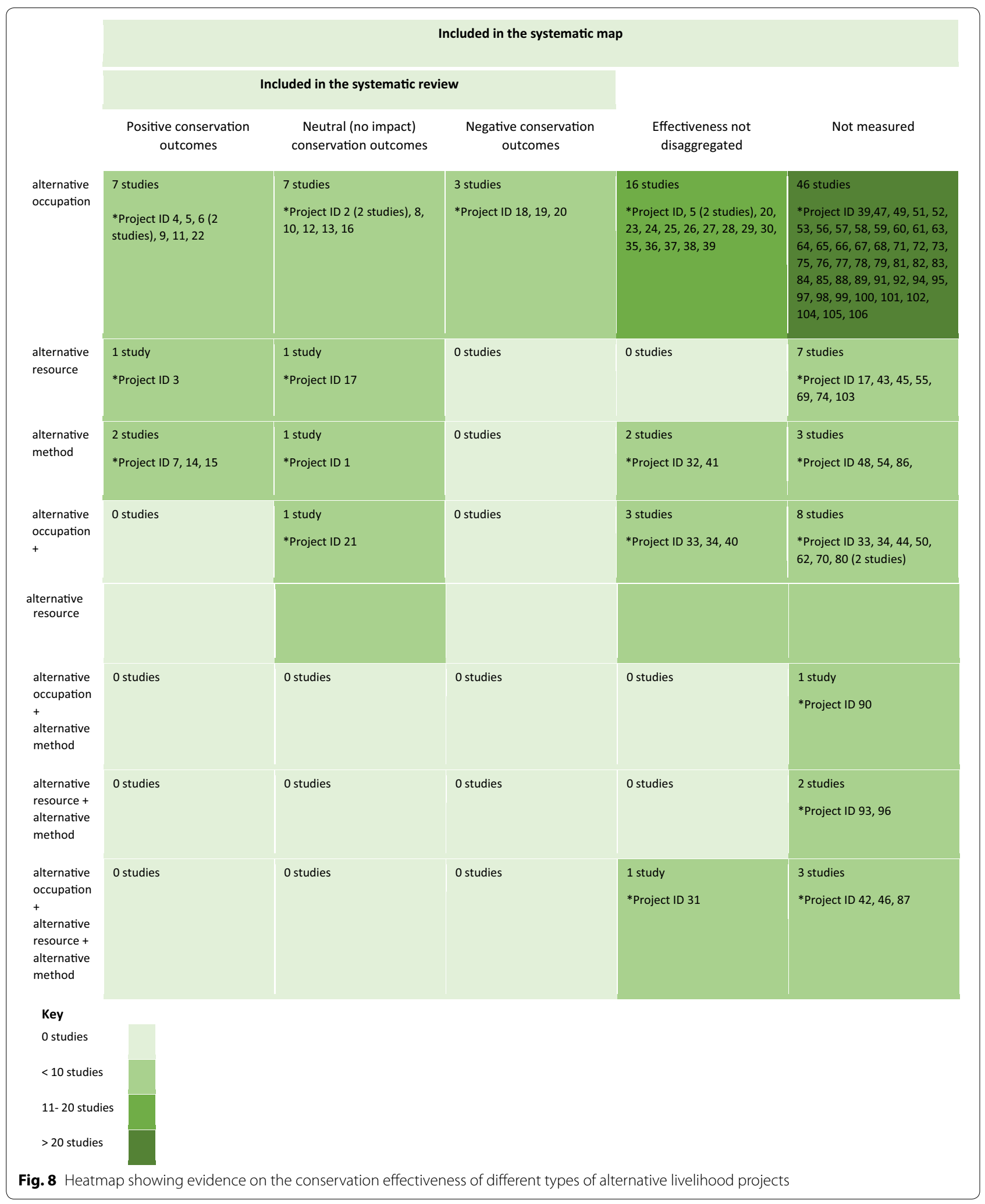


The 20 studies that were included in the systematic review described 21 projects. Two projects, the Amani Butterfly Farming in Tanzania $[45,46]$ and ProManejo in Brazil $[47,48]$, were each assessed in two different studies (in both cases, the same conclusions on conservation effectiveness were reached in the separate studies). In the case of the ProManejo project the two studies were compiled by the same authors, and so cannot be viewed as two assessments that are independent of one another. The two studies on the Amani Butterfly Farming project were conducted by different authors. One study [45] covered three different projects and assessed each of these separately and so a separate analysis of each case study is included in the synthesis below. The final list of included studies and projects is detailed in Additional file 9.

For the purposes of narrative synthesis, the studies (including both qualitative and quantitative studies) have been grouped according to the broad conservation outcomes that they described: positive (for example, a favourable change in attitudes to conservation, or behaviour of the threat group, or an improvement in the conservation status of the biodiversity target), neutral (no impact on attitudes, behaviour or conservation status) and negative (detrimental impact on attitudes, behaviour or conservation). The number of studies that report on these broad outcomes is described in the narrative and shown in Fig. 9, along with the type of measure (whether changes in attitudes, behaviour or conservation status) used to determine effectiveness. These numbers do not imply that one outcome is more or less likely than the other, but simply reflect the numbers of studies that have been conducted of projects that have shown these outcomes.

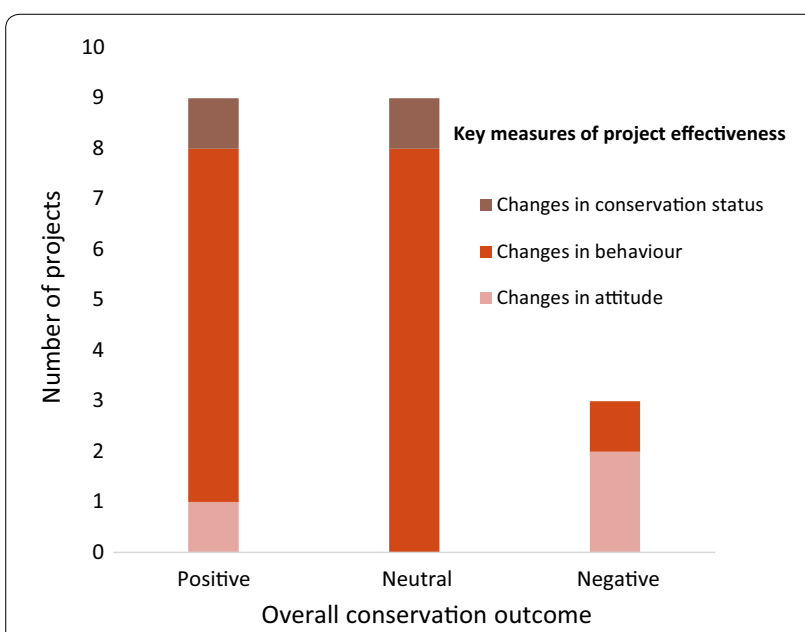

Fig. 9 The reported biodiversity conservation outcomes of the 21 projects

\section{Positive outcomes}

- Nine studies referring to nine alternative livelihood projects reported positive outcomes. One study [45] assessed two different projects and two studies [45, 46] assessed the same project.

- The nine studies described nine alternative occupation interventions, two alternative method interventions and one alternative resource intervention.

- Only one study [49] measured conservation effectiveness in terms of an improvement in the conservation status of the biodiversity target.

- Four studies were rated as strong reliability in the critical appraisal exercise, four medium reliability, and one weak reliability.

- Five studies presented quantitative evidence, three of which used a quasi-experimental approach, and four studies described qualitative or mixed evidence.

- Three studies were conducted by project implementers and six studies were carried out by third party researchers.

\section{Changes in conservation status of biodiversity target}

The only evidence of a project using an alternative livelihood that led to a positive change in the conservation status of a biodiversity target came from a single study of a project to conserve the Sichuan Golden Snub-nosed Monkey [49]. The project promoted the use of fuel-efficient stoves as a way to reduce fuelwood consumption in the Tuhe Nature Reserve in China- a key habitat for the monkey. The study by DeWan et al. was written by the project implementers (a potential source of bias) and ranked as medium reliability following critical appraisal.

DeWan et al. used a quasi-experimental approach to evaluate shifts in attitudes, behaviour change, stove adoption and fuelwood consumption, and overall forest impacts following project implementation. Overall, $43.1 \%$ of households studied were reported to be using fuel-efficient stoves 2.5 years after project completion. In addition, "Forest monitoring revealed a $23.7 \%$ reduction in tree-felling for fuel wood in forest surrounding villages where fuel-efficient stoves were used in place of conventional stoves" (pp. 35). The study emphasised that further significant improvements in the biodiversity and forest quality of the Yuhe Reserve were expected in 5 years after the intervention, and that the results reported should be considered as mid-term results only.

Changes in behaviour of people posing a conservation threat Novriyanto et al. [50] used a quasi-experimental approach to assess the performance of a micro-credit revolving fund project through self-reported changes in environmental attitudes and behaviour in the post-tsunami community of Iboih, Indonesia (ranked as strong 
reliability in critical appraisal). Aimed at fisherfolk, the project provided loans in return for not practicing destructive fishing (e.g. spear fishing). The authors found that 12.8 and $7.7 \%$ of the project participants stated they no longer disturb coral or practice dynamite fishing respectively. Other changes in behaviour included increased reporting of violations of regulation and increased awareness of the need to abide by conservation principles. The authors noted, however, that their study was unable to clearly separate the impacts of the revolving fund from confounding factors including other conservation activities occurring over the same time period.

Mijanur-Rahman and Begum [51] also reported this limitation to their study (low reliability) of the Management of Aquatic Ecosystems through Community Husbandry $(\mathrm{MACH})$ project in Bangladesh. They found that the introduction of multiple alternative occupations to wetland resource users had the desired effect of increasing income and decreasing fishing effort, but they noted that restrictions on fishing (e.g. seasonal closures) that were unrelated to the alternative livelihood interventions had likely contributed significantly to this change in behaviour.

In a quasi-experimental study (strong reliability) of the effect of the alternative occupation of butterfly farming in the East Usambara Mountains of Tanzania, Morgan-Brown et al. [46] found evidence to support their hypothesis that income dependency on butterfly farming was positively associated with participation in forest conservation. Yet, they noted that the behaviour change appeared to be dependent on the amount of income earned: 'Butterfly famers with the lowest income did not report significantly more participation in conservation than the control group' (pp 570). Additionally, land ownership appeared to be a significant predictor of conservation behaviour-the authors suggested that land ownership might act to free up labour and give people more of an opportunity to risk effort on a new, alternative livelihood, as well as making it easier to set aside forested areas for conservation.

Another study of the same project (moderate reliability) by Engh [45] reported similar positive behaviour change. In one village, for example, 34 butterfly farmers had come together to buy a plot of land to plant trees attractive for butterflies in order to increase the larvae fodder and butterfly populations. Engh added a note of caution however, that respondents suggested that this behaviour change might be reversed and that they might revert to agricultural crops if the butterfly market changes and incomes decline.

Langholz [52] identified a similar market issue in a study (strong reliability) on the impact of a homestay project in the buffer zone of the Maya Biosphere
Reserve in northern Guatemala. The homestay project was intended to relieve pressure on forest exploitation, in particular from logging, farming and cattle ranching. The initiative appears to have been successful in that over a 4 year period from 1994 to 1997, the area under cultivation in the buffer zone decreased by $39 \%$ (from 45.2 ha to 27.7 hectares) and 'two-thirds of the anfitrionas [homestay hostesses] said they were less dependent on the forest in 1996 than they were 3 years prior' (pp. 145). Despite this, Langholz noted the potentially transient nature of such behaviour changes, particularly where external conditions can affect the success of an initiative. In this case, for example, increased guerrilla activity or a reduction in international visitors could reverse any adjustment caused by the homestay project.

A further study of tourism (moderate reliability) by Stronza [53] evaluated the Posada Amazonas project in Peru and found that community members who worked at the lodge invested less time in shifting cultivation or hunting. Though, this behaviour change was documented in only 12 of approximately 80 households in the community and overall, Stronza concluded that the effect of ecotourism was ambiguous and considered that different kinds of participation in ecotourism could lead to contrasting impacts on natural resource use. So while direct participation might lead to decreased natural resource use (i.e. through creating economic time constraints) other forms of participation (i.e. selling goods and services to the ecotourism lodge) may not have the same effect. In some cases income from ecotourism was invested in chainsaws, motorboats and other equipment. While the impact of these investments on biodiversity was not measured in the study, Stronza suggests that there could potentially be a resulting negative impact.

The final two studies (moderate reliability) in this subsection considered an alternative resource and an alternative method. Nautiyal [54] found that in the Indian Himalayas, the introduction of Liquid Propane Gas (LPG) stoves had changed behaviour and reduced fuelwood consumption from $475 \mathrm{~kg} / \mathrm{capita} /$ year in 1983 to $47 \mathrm{~kg} / \mathrm{capita} /$ year in 2003 although, in villages located far from roads, fuelwood consumption remains high due to the high transport costs of LPG. Engh [45], meanwhile, found narrative data that suggested that the alternative method of feeding cattle in enclosures (rather than clearing the forest for grazing) had been adopted as part of the Tanga Small Scale Dairy Project to protect the Amani Forest Reserve. The author underlined, however, that while the desired effect of reducing forest clearance had been achieved, in times of low rainfall, farmers were increasingly inclined to feed the cattle with fodder collected from the forest rather than that grown on their own land. 


\section{Changes in attitudes to conservation}

Islam and Nath [55] was the only study in this section that did not go beyond changes in attitude as an indicator or conservation effectiveness. In this moderate reliability study of betel farming in Lawachara National Park, Bangladesh, the indigenous Khasia were given a hectare of land to farm betel leaves as an alternative occupation to slash and burn agriculture and livestock grazing. The study found that most of the households had a positive attitude towards the park which the authors attributed to the success of the betel leaf farming initiative. Yet, authors highlighted that these positive attitudes were not universal and some respondents expressed negative attitudes, mostly associated with human wildlife conflict, product marketing and the behaviour of Forest Department staff.

\section{Neutral outcomes}

- Ten studies were identified, documenting nine projects (two studies $[47,48]$ assessed the same project).

- The nine alternative livelihood projects included six alternative occupation interventions, one alternative method intervention and two projects that comprised both alternative resource and alternative occupation interventions.

- Only one study used change in conservation status as its measure of effectiveness; all the others used change in behaviour.

- Three studies (two of the same project) were rated as strong reliability, five studies rated moderate reliability and two studies as weak reliability.

- Two studies provided quantitative evidence, one study detailed qualitative evidence, and seven studies presented mixed evidence.

- All were conducted by third party researchers.

The ProManejo ICDP project in the Brazilian Amazon was assessed by two studies $[47,48]$, both rated as strong reliability from the critical appraisal. The project introduced a range of small enterprises (including sales of various non-timber forest products and ecotourism) as a way to reduce pressure on the Tapajos National Forest. Bauch et al. [47], was the only study which assessed the conservation status of the biodiversity target. In this case, Landsat data was used to explore changes in forest cover over time and the authors found no evidence of changes in deforestation rates by communities with the introduced enterprises and those without. Weber et al. [48] similarly found no evidence that participation in the project reduced the amount of forest used for agriculture by local people.

Hill et al. [56], in a quantitative assessment of fisherfolk numbers (rated as strong reliability), examined the effectiveness of seaweed farming as an alternative occupation to fishing in eight villages in the Philippines. They identified positive outcomes in four villages but negative outcomes in another four. The rationale for introducing seaweed farming to these villages was to reduce unsustainable fishing by reducing the numbers of fishers, but in four of the villages fisher numbers were reported to have increased rather than decreased. In these cases, seaweed farming was not perceived as a viable alternative to fishing but rather as an additional source of sporadic income for non-daily household needs such as school fees. Furthermore, in the villages reporting a positive outcome (i.e. a decrease in the number of fishers) the change was associated with an increase in world prices for seaweed alongside declining fish catches making fishing income less reliable than income from seaweed. As with the studies reporting positive outcomes discussed above, the implication is that a price change in the opposite direction would be likely to result in a swing back to fishing.

Five further studies rated as moderate reliability in this sub-section and covered a wide range of interventions. Eastmond and Faust [57] studied the Mucuna-maize cropping project in Sahcaba, Mexico that attempted to introduce an alternative method of agricultural production in order improve soil conditions so that farmers would switch from shifting agriculture (which resulted in deforestation) to permanent agriculture. Schubauer and Koch [58] assessed the Pesca Artesanal Vivencial (PAV) project in the Galapagos Marine Reserve (GMR) which promoted ecotourism (recreational fishing trips) as an alternative occupation to fishing for lobster, sea cucumber and other resources within the GMR. Engh [45] studied the Novella Africa partnership that promoted the production of Allanblackia trees on homesteads in order to reduce illegal offtake from the forest in the Amani Nature Reserve, Tanzania. Blomley et al. [59] studied a range of interventions around Bwindi Impenetrable and Mgahinga Gorilla National Parks in Uganda designed to reduce illegal and unsustainable use of forest resources such as hunting. And Herrold-Menzies [60] studied the impact of micro-enterprise development as a way to reduced dependence on wetland resources in the Caohai Nature Reserve, China.

In the maize project there was limited uptake of the new method due to higher labour inputs required for no significant increase in yield and so shifting cultivation continued. Similarly in the fishing project there was limited success with the ecotourism venture, due to competing interests between artisanal and sports fisheries stakeholders and a lack of promotion of the artisanal fisheries. As a result there was no significant reduction in fishing pressure. With the Allanblackia project the issue was not so much one of limited uptake but more to do 
with problems with propagating Allanblackia in the tree nurseries and the long time period between germination and harvesting which meant that people continued to harvest from the forest in addition to having trees on their land. Similarly in the Bwindi/Mgahinga ICDP project Blomley et al. reported no reduction in illegal harvest of trees adjacent to areas where trees had been planted on farms with high tree planting rates. Overall the substitution approach had no discernible impact on the mitigating the primary conservation threat, which was unsustainable use of resources in the two parks. The microenterprise scheme in Caohai Nature Reserve, China also showed no significant change in local people's dependence on wetland resources despite the proliferation of enterprises. Indeed, the authors pointed out that in in some cases the enterprises may have had a damaging effect (although this was not assessed) in that there was an increase in pig farming and the use of fertilisers, which may have increased the run off of pollutants into the reserve wetlands.

Two studies that rated as weak reliability also reported limited behaviour change as a result of project interventions. The Cham Island Marine Protected Area (MPA) project assessed by Brown [61] provided narrative evidence to show that small enterprises designed to reduce fishing pressure did not generate sufficient income to provide a viable alternative to fishing. For the few participants that did succeed in the business the income was seen as supplementary to fishing income rather than a substitute. The Eco-Development project in Sasan Gir National Park and Sanctuary assessed by Varma [62] provided non-wood sources of fuel and construction materials in an attempt to reduce pressure on forest resources but found limited uptake because of a cultural preference for cooking with wood rather than LPG. Meanwhile the "Bella stones" that were distributed for construction purposes were not used for the purpose for which they were intended and timber extraction from the forest continued.

As well as changes in behaviour the studies by Blomley, Herold Menzies and Engh also measured changes in attitudes to conservation by project participants. Both Blomley and Herold Menzies reported that relations between local communities and protected area staff had improved as a result of the projects-although this was reported as a secondary outcome compared to the limited changes in behaviour. Engh provided narrative information that indicated attitudes to conservation had improved as a result of the Allanblackia project.

\section{Negative outcomes}

- Two studies were identified $[63,64]$ describing three alternative livelihood projects.
- Both studies focus on alternative occupations.

- One study based the assessment of effectiveness on changes in attitudes and one on changes in behaviour.

- One study was rated as moderate reliability in the critical appraisal exercise; the other was rated moderate for one case study and weak reliability for the second.

- One study described mixed (qualitative and quantitative) evidence, while the other reported qualitative evidence.

- Both studies were conducted by third party researchers rather than project implementers.

Brock [63] examined the introduction of alternative occupations through a micro-credit scheme as a mechanism to reduce fishing pressure in the Spermonde Archipelago of South Sulawesi. The study (moderate reliability) found narrative evidence to suggest that the most common use of microcredit funds was to purchase additional fishing equipment, and it did not encourage participants to change their behaviour and build other non-fishing based enterprises. Furthermore, Brock underlined that the purchase of the additional fishing gear had the potential to increase fishing pressure and have negative biodiversity conservation outcomes (though this was not assessed). One of the reasons given for the failure of the initiative was that the loans were not sufficient to start a viable alternative business.

Martinez-Reyes [64] conducted an ethnographic study of two alternative livelihood projects implemented in the Tres Reyes village of Mexico's Sian Ka'an Biosphere Reserve. The first project issued quotas to allow local communities to capture and sell parrots for the pet trade as an alternative to illegal use of forest resources (including hunting) and to supplement subsistence agriculture-based livelihoods. The study (moderate reliability) described narrative data highlighting how the project was beset with bureaucratic delays. The project caused so much frustration that as a result the local community 'ceased collaborating with any entity on conservation issues' ( $\mathrm{p}$ 169). Overall, the study found that the parrot project had caused a deterioration in attitudes towards conservation-or at least towards state or NGO-led conservation initiatives.

The second alternative occupation project studied by Martinez-Reyes (categorized as weak reliability) was targeted specifically at women in Tres Reyes and introduced the idea of using butterfly wings (from the large numbers of butterflies that could be found killed along the nearby main road) for craft-making. The project was described as time consuming with no apparent identification of a viable market for the crafts and was eventually 
discontinued. As with the parrot project, the butterfly project resulted in local dissatisfaction with externallydriven conservation initiatives-'The perceived wisdom in Tres Reyes was that the majority of development projects had produced no positive outcomes. Communities had become increasingly sceptical about foreigners' intentions.' (p171).

\section{Discussion}

This review both outlines the current evidence base on the effectiveness of alternative livelihood projects (the systematic map) and assesses whether or not such projects have succeeded in delivering conservation outcomes, as measured by changes in the attitudes or the behaviour of the people identified to be causing a threat to conservation and/or by changes in the conservation status of the biodiversity target (the systematic review). The review was motivated by a concern that considerable amounts of conservation funding are allocated to alternative livelihood projects, despite the lack of evidence of conservation impact, and as such we only included evidence that measured effectiveness from a conservation perspective. We did not seek to explore the livelihood impacts of alternative livelihood projects, but recognise that in some cases they may have contributed to local peoples' livelihoods even if they did not necessarily have positive conservation impacts. We identified 97 studies that documented the conservation effectiveness of 106 alternative livelihood projects but rejected many more studies that only assessed projects from a socioeconomic perspective, thus we acknowledge the limitations of the available evidence base with regard to livelihood outcomes.

\section{Strengths and limitations of the review}

This review is the first of its kind to explore the effectiveness of alternative livelihood projects. As noted previously, the only comparable study is a review of bushmeat substitution projects in Africa [4] and so this study greatly enhances the existing knowledge base on such projects. Nevertheless, this review is limited by the paucity of evidence available. The collected studies identified a wide range of different types of alternative livelihood interventions being used to address an equally wide range of threats and conservation targets, but we were unable to determine trends in terms of the relative effectiveness of one type of intervention compared to another. We were, though, able to characterise the projects in terms of the broad types of interventions used, and the locations of their deployment.

The diversity of the studies we captured limits the ability to statistically assess publication bias within the systematic review. Our search strategy aimed to minimise publication bias by including a comprehensive search of both the grey and formal literature [65]. However, much of the grey literature was descriptive rather than analytical with few evaluations of projects publically available or accessible (or perhaps even undertaken). Of the 21 studies that met the inclusion criteria for the systematic review, 16 were from formal literature sources (e.g. journal publications), and four were from the grey literature. Sixteen of the 21 studies were undertaken by independent researchers rather than project implementers thus limiting the scope for researcher bias to some extent.

\section{Reasons for heterogeneity}

The degree of heterogeneity in the results was striking. There was limited reporting on the potential effect modifiers that we identified in our protocol, including the presence of a contractual agreement; local design of the project; the project's dependence on conservation outcomes; and the specific targeting of individuals or groups causing the biodiversity threat. The data collected on each of these variables were insufficient to allow us to draw any firm conclusions as to whether or not these affected the outcome of the alternative livelihood interventions.

One of the main reasons for heterogeneity is that alternative livelihood interventions need to be designed specifically for the local context, and that there is always the possibility of perverse incentives. This is reflected strongly in those studies that reported positive outcomes in some cases and negative outcomes in others when the alternative intervention deployed was the same and it would appear that the contexts in which it was deployed were similar. It remains to be seen whether the measurement of any particular variables before the introduction of an alternative livelihood can help predict conservation outcomes.

\section{Limitations of the evidence base-}

We only found 21 studies with measurements of the conservation effectiveness of alternative livelihood projects, meaning that there was a very limited evidence base with which to address our primary research question (furthermore one of these studies was then eliminated following critical appraisal). In addition, just five studies (covering four projects) received a strong reliability score following critical appraisal. This was because many of the studies did not specify the sampling frame (the number of people subject to the alternative livelihood intervention) and failed to adequately account for confounding variables that may have influenced the project outcomes. Moreover, we observed that the comparator used by studies was extremely variable; often a baseline survey was conducted prior to the intervention, but occasionally 
adjacent communities or individuals not subject to the intervention were used as controls.

Only two studies measured changes in the conservation status of the biodiversity target, with one of these being a rudimentary assessment of the number of tree stumps around a village as an indication of deforestation rate. A large number of the studies assessed behaviour and attitude among local community members through the use of questionnaires. As many of these projects also intended to provide livelihood benefits to recipients of the questionnaires, there is the possibility of respondent bias in reporting positive conservation outcomes. Few studies acknowledged this potential and did not specify how participants had been selected to reduce the likelihood of biased responses.

It is also important to underline here that three of the studies that reported a positive impact of an alternative livelihood project were conducted by project implementers. This is in contrast to those studies finding a neutral or negative impact which were all conducted by third party researchers. Although, this is a small sample size, the apparent lack of independence of some authors reporting positive outcomes is worth highlighting.

Despite the pervasive nature of alternative livelihood projects and their integration into current conservation practice, it is surprising how few studies actually provided any verifiable measure of the effectiveness of such projects. Our "heatmap" of evidence (Fig. 8) shows that there is considerably more evidence of a descriptive nature that makes no attempt to assess effectiveness than of any other kind. It was also surprising how few studies measured effectiveness in terms of actual improvements in the conservation status of a specified biodiversity target. The majority measured changes in the attitudes and/ or behaviours of the group(s) of people posing a threat to conservation without exploring whether that change in attitude or behaviour had actually resulted in a reduction in threat and/or a subsequent improvement in conservation status-as per the RARE theory of change [19]. The fact that case study authors not infrequently commented on the potential reversibility of changes in attitudes and/ or behaviours there should be concern about the further weakening of the evidence base for the long-term effectiveness of alternative livelihood projects.

The data were also insufficient to draw conclusions as to which types of projects are more successful than others, and thus broader scaling up of findings is problematic. Another major shortfall that seems to characterise the literature is the strong emphasis on "linear" and time-bound reporting. In other words, projects report on what they did and what impacts these interventions had. There was little or no integration of the counterfactual, i.e. what would have happened if there had not been such interventions? In addition, the influence of the external economic and natural environments is not taken into account when assessing the "impacts" of project interventions. These may be considerable (e.g. road construction, commodity price changes) yet are rarely brought into discussions surrounding the impacts of project interventions alone.

\section{Review conclusions}

This review sought out the evidence to answer the question "Are alternative livelihood projects effective at reducing local threats to specified elements of biodiversity and/or improving or maintaining the conservation status of those elements?" Our search of the published and grey literature identified 106 projects reporting alternative livelihood interventions. Conservation effectiveness was measured in only 21 of these, of which only nine reported that the intervention was effective in either improving local attitudes to conservation, reducing environmentally-damaging behaviour, or improving the conservation status of a biodiversity target. It is important to note, however, that for many of the projects it was difficult to be conclusive about effectivenesssome projects operating in multiple sites were successful in some sites and not in others and there appears to be no robust way of predicting what might be the key causal factor. Understanding causality would require the establishment of interventions in an experimental research design, allowing them to be compared with appropriate controls or counterfactuals. In the case of most of the alternative livelihood projects we identified the interventions have not been introduced in this way and, even if they were, the contexts in which they are deployed are so widely different that the learnings from one site to another would still be limited. Where projects could improve is by developing a solid theory of change for their interventions and being clear about the assumptions on which the theory of change rests, and testing and reviewing the assumptions as the project progresses. In the absence of more robust assessment we conclude there is currently insufficient evidence to say when and where alternative livelihood projects work, or even why they work.

\section{Implications for policy and management}

As in many other cases in conservation and development investment there is scant attention paid to the evidence base underlying the investment. Implementers, policy makers and funders are drawn to supporting conservation strategies for a complicated set of reasons, few of which are based on measured assessments of evidence. This yawning gap in evidence of effectiveness underpinning much of conservation and development is a strong 
reason for the compelling need for systematic reviews such as this.

Our results show that there has been a wide and deep investment in alternative livelihood projects-our search documented hundreds of projects on five continents. Yet neither the structure of most of these projects nor their results have been documented in a way available to our searches, which were comprehensive and extended well beyond simple literature searches.

Our work has a number of policy and management implications specifically for alternative livelihood projects and more generally for conservation investments. Implementation of the recommendations below would dramatically improve the ability of projects to monitor effectiveness and understand causal linkages between their project activities and conservation outcomes:

1. Performing a systematic review before beginning significant investments in a new area should be a sine qua none. Such a review can then inform both the decision to proceed as well as the nature of the investment. This review should be focused not only on the specific intervention planned, but also on understanding the system within which it operates and the role of the activities that they are attempting to substitute for within the livelihood strategy.

2. If the systematic review does not reveal a solid evidence base on which to begin the program then investments should be constructed in a formalised adaptive management framework that allows testing and learning - both by project implementers and those outside the project.

3. In particular, all projects involving alternative livelihood should have a "theory of change" (TOC) [66]. The TOC approach, originated in the social services sector, and is a process of project planning and evaluation that maps the relationship between a longterm goal of a project and the intermediate and early changes required to bring it about. It makes explicit the explanation of the way a project is understood to reach its goals, and the process through which changes will occur. Best practices in the use of TOC emphasise the theory and assumptions underlying the pathway of change. Use of a TOC in all future alternative livelihood projects would make specific the logic through which the implementer believes the intervention would work and allows them to learn and share.

4. All too often alternative livelihood projects do not specify the biodiversity outcome they wish to achieve, let alone put in place a monitoring system for determining the impact of the project on the biodiversity target. Both specification of the target and implementation and publishing of the monitoring results must become part of all such projects. Livelihood projects are often components of a broader landscape of measures that influence conservation outcomes. This can make it challenging to design $M \& E$ programmes and address issues of causality. However, the TOC identifies what contribution each particular intervention is expected to make towards the conservation outcome, and can make it easier for projects to develop indicators of success relating to specific interventions or project activities.

5. The TOC should be developed as a specific part of a larger "systems map" of the larger context within which the alternative livelihood project is being implemented. Such a map spells out the broader context in which the project operates including local livelihood economies, value chain analysis, and what links each intervention would have to potentially better, and explicit, environmental outcomes, and whether causality can be proven.

6. All alternative livelihood projects should include an assessment of the risks of the intervention and only include possibilities that have been vetted by local stakeholders. Introducing new technologies, changing longstanding practices, or altering social relations with new income streams are all complicated, and potentially fraught activities. They might result in negative impacts to the local populations and/ or might have negative impacts on biodiversity (as shown in some of the projects discussed above).

7. Part of this risk assessment must be an examination of the sustainability of the intervention. The shortterm nature of most project-based interventions means that alternative livelihood activities introduced in a given project might not be supported until they become accepted without further outside support.

8. Lastly, and most importantly, the considerable work that has been undertaken on implementing alternative livelihood projects does not provide compelling evidence that they work. However, the evidence also does not allow any clear determination of why they usually don't work, or why they occasionally do. Future work must focus on project design, monitoring and sharing of lessons.

9. Funders should actively encourage projects to report both positive and negative experiences of alternative livelihood interventions, so that genuine progress can be made through field-based experience.

\section{Implications for research}

It is clear that we do not understand why most alternative livelihood projects do not work, and why a small handful of them do. The evidence base assembled for this review 
provides an excellent starting point for further work-particularly involving interviews with project implementers, from whom many missing details would undoubtedly be gleaned.

The field of conservation requires a set of best practice guidelines for the evaluation of alternative livelihood projects. Perhaps this review, given it has identified many of the shortfalls in design, methodology and evaluation could elucidate the first stage of that process.

\section{Additional files}

Additional file 1. A list of search terms.

Additional file 2. The scoping strategy used for bibliographic databases.

Additional file 3. List of journals covered by the PCLG digest.

Additional file 4. The search strings used for internet search engines.

Additional file 5. Unsourced studies and studies excluded at full text.

Additional file 6. Data extraction sheet.

Additional file 7. List of 106 projects included within the systematic map.

Additional file 8. Critical appraisal scores.

Additional file 9. Systematic review studies following critical appraisal.

\section{Authors' contributions}

$\mathrm{DR}, \mathrm{MD}, \mathrm{FB}$ and TS co-drafted the manuscript. DR provided oversight and management of the research. MD, FB led the data extraction and analysis with contributions from WZ, SAW and DR. GP provided technical support throughout the project and DR, NK and GS contributed to the data extraction strategy design and commented on earlier drafts. All authors read and approved the final manuscript.

\begin{abstract}
Author details
${ }^{1}$ International Institute for Environment and Development (IIED), 80-86 Grays Inn Road, London WC1X 8NH, UK. ${ }^{2}$ Centre for International Forestry Research (CIFOR), Jalan CIFOR, Situ Gede, Sindang Barang, Bogor 16115, Indonesia. ${ }^{3}$ Zoological Society of London (ZSL), Regent's Park, London NW1 4RY, UK. ${ }^{4}$ Department of Zoology, Conservation Science Group, University of Cambridge, Cambridge CB2 3EJ, UK. ${ }^{5}$ Department of Zoology, University of Oxford, The Tinbergen Building, South Parks Road, Oxford OX1 3PS, UK. ${ }^{6}$ Archipelago Consulting, P.O. Box 4750, Portland, ME 04112-4750, USA. ${ }^{7}$ United States Agency for International Development, Washington, DC, USA. ${ }^{8}$ International Development Department, London School of Economics and Political Science, Houghton Street, London WC2A 2AE, UK. ${ }^{9}$ Imperial College Conservation Science, Department of Life Sciences, Imperial College London, Silwood Park Campus, Buckhurst Road, Ascot SL5 7PY, UK.
\end{abstract}

\section{Acknowledgements}

The authors would like to thank Michelle Wieland for providing inputs into the design of this study and for commenting on earlier drafts of this paper. Support for this study was provided by the Centre for International Forestry Research (CIFOR) through its evidence-based forestry initiative, which is funded by a grant to CIFOR from the UK's Department for International Development (DFID) through its KNOW-FOR program grant to CIFOR, and funding partners who have contributed to the CGIAR Fund. Additional financial support provided by the United States Agency for International Development (USAID). We would also like to thank staff of the Bodleian library, University of Oxford for help locating sources of evidence.

\section{Competing interests}

The authors declare that they have no competing interests. One co-author (Nick AO Hill) is an author on one document included in the systematic review. Similarly one co-author (Kent Redford) is an author on one document included in the systematic map. However, neither $\mathrm{NH}$ or KR were involved in article screening or data extraction.

Received: 7 July 2015 Accepted: 21 October 2015

Published online: 17 November 2015

\section{References}

1. Secretariat of the Convention on Biological Diversity. Livelihood alternatives for the unsustainable use of bushmeat. Report prepared for the CBD Bushmeat Liason Group. Technical Series No. 60, Montreal, SCBD. 2011. p. 46.

2. Foerster S, Wilkie DS, Moreli GA, Demmer J, Starkey M, Telfer P, Steil M, Lewbel A. Correlates for bushmeat hunting among remote rural households in Gabon, Central Africa. Conserv Biol. 2012;26:335-44.

3. Abernethy KA, Coad L, Taylor G, Lee ME, Maisels F. Extent and ecological consequences of hunting in Central African rainforests in the twenty-first century. Phil Trans R Soc B. 2012;368:1-11.

4. Wicander S, Coad L: Learning our Lessons: A Review of Alternative Livelihood Projects in Central Africa. Oxford, UK: ECI, University of Oxford and Gland, Switzerland: IUCN. (http://www.eci.ox.ac.uk/publications/downloads/wicander-coad-english2015.pdf) Accessed online June 2015.

5. Triet R. Combining biodiversity conservation with poverty alleviation-a case study in the Mekong Delta Vietnam. Aquat Ecosyst Health Manage. 2010;13:41-6

6. Munthali S, Mughogho D. Economic incentives for conservation: beekeeping and saturniidae caterpillar utilization by rural communities. Biodivers Conserv. 1992;1:142-54.

7. Sievanen L, Crawford B, Pollnac R, Lowe C. Weeding through assumptions of livelihood approaches in ICM: seaweed farming in the Philippines and Indonesia. Ocean Coast Manag. 2005;48:297-313.

8. Hill N, Rowcliffe M, Koldewy H, Milner-Gulland EJ. The interaction between seaweed farming as an alternative occupation and fisher numbers in the Central Philippines. Conserv Biol. 2011;2:324-34.

9. DeWan A, Green K, Li X, Hayden D. Using social marketing tools to increase fuel-efficient adoption for conservation of the golden snubnosed monkey, Gansu Province, China. Conserv Evid. 2013;10:32-6.

10. Lui M, Sadovy de Mitcheson Y. Profile of a fishery collapse: why mariculture failed to save the large yellow croaker. Fish Fish. 2008;2008:219-42.

11. FFI. Why not "alternative livelihoods"? Conservation, Livelihoods and Governance Programme. Cambridge: Fauna and Flora International; 2013.

12. Mansfield D, Pain A. Alternative livelihoods: substance or slogan? Afghanistan Research and Evaluation Unit (AREA) Briefing Paper, 2005. Kabul, Afghanistan.

13. Carney D (Ed): Sustainable rural livelihoods: what contribution can we make? Department for International Development's Natural Advisers' Conference, July 1998; London: Department for International Development (DfID); 1998.

14. Brown K. Three challenges for a real people-centred conservation. Glob Ecol Biogeogr. 2003;12:89-92.

15. International Union for the Conservation of Nature (IUCN): Motion 145. World Conservation Congress, 6-15th September 2012; Jeju, Korea; 2012. Accessed online June 2015. (https://portals.iucn.org/docs/2012congress/ motions/en/M-145-2012-EN.pdf).

16. US Agency for International Development (US AID)/Central Africa Regional Program for the Environment (CARPE) Regional Development Cooperation Strategy 2012-2020, pp 1-38.

17. UNDP: Tackling a root cause of Ebola, the bushmeat trade. Ebola Recovery in Sierra Leone. UNDP 2015. http://www.sl.undp.org/content/dam/ sierraleone/docs/Ebola\%20Docs./SL\%20FS\%20Tackling\%20the\%20Bushmeat\%20Trade.pdf. Accessed online September 2015.

18. Wright J, et al. Reframing the concept of "alternative livelihoods". Conserv Biol. 2015;. doi:10.1111/cobi.12607.

19. Rare: Theory of Change for Community Based Conservation. http:// www.50in10.org/wp-content/uploads/2013/12/ToC_Booklet_Final_ Nov2013b.pdf. Accessed online Sept 2015.

20. Roe D, Day M, Booker F, Zhou W, Allebone-Webb S, Kümpel N, Hill NAO, Wright J, Sunderland TCH, Redford K, Petrokofsy G. Are alternative 
livelihood projects effective at reducing local threats to specified elements of biodiversity and/or improving or maintaining the conservation status of those elements?: a systematic review protocol. Env Evidence. 2014:3:1-8

21. Scopus (http://www.scopus.com/).

22. Web of Knowledge (http://wok.mimas.ac.uk/).

23. CAB Abstracts (http://www.cabi.org/).

24. AGRIS (http://agris.fao.org/agris-search/index.do).

25. AGRICOLA (http://agricola.nal.usda.gov/).

26. African Journals Online (http://www.ajol.info/)

27. Asian Journals online (http://www.asiajol.info/)

28. Directory of Open Access Journals (https://doaj.org/).

29. PCLG Journals Digest (http://povertyandconservation.info/en/ news-blogs).

30. Google (https://www.google.co.uk).

31. Google Scholar (https://scholar.google.co.uk)

32. DART-Europe E thesis (http://www.dart-europe.eu/browse.php).

33. Ethos (http://ethos.bl.uk/)

34. National ETD Portal South Africa (http://www.netd.ac.za/)

35. Open Access Theses and Dissertations (http://oatd.org/).

36. ProQuest Digital Dissertations and Theses (http://www. proquest.com/ products-services/pqdt_uk_ireland.html).

37. Systeme Universitaire de Documentation (http://www.sudoc.abes.fr).

38. Poverty and Conservation Learning Group (http://povertyandconservation.info/).

39. Biodiversity List (http://www.iisd.ca/email/).

40. Day M, Are 'alternative livelihoods' projects effective? 2014. (http://www. iied.org/are-alternative-livelihoods-projects-effective).

41. UK Bushmeat Working Group (http://www.zsl.org/conservation/regions/africa/bushmeat-in-west-and-central-africa/ uk-bushmeat-working-group).

42. The Cochrane Risk of Bias Tool (http://bmg.cochrane.org/assessingrisk-bias-included-studies\#The\%20Cochrane\%20Risk\%20of\%20Bias\%20 Tool).

43. Quality Assessment Tool for Quantitative Studies (http://www.ephpp.ca/ PDF/Quality\%20Assessment\%20Tool_2010_2.pdf).

44. Birdlife International Data Zone (http://www.birdlife.org/datazone/info/ spchabalt).

45. Engh V. Integrated conservation and development projects and efforts Around the Amani Nature Reserve Tanzania, and their effects on livelihoods and forest conservation. Dissertation submitted to the Norwegian University of Life Sciences. Accessed online June 2015: (http://brage bibsys.no/xmlui/bitstream/handle/11250/187743/Final\%20Master\%20 Thesis\%20Vegard\%20Engh.pdf? sequence=1).

46. Morgan-Brown T, Jaconson SK, Wald K, Childs B. Quantitative assessment of a Tanzanian integrated conservation and development project involving butterfly farming. Conserv Biol. 2010;24:563-72.

47. Bauch SC, Sills EO, Pattanayak SK. Have we managed to integrate conservation and development? ICDP impacts in the Brazilian Amazon. World Dev. 2014;64:135-48.

48. Weber JG, Sills EO, Bauch S, Pattanayak SK. Do ICDPs Work? An empirical evaluation of forest-based microenterprises in the Brazilian Amazon. Land Econ. 2011;8:661-81.

49. DeWan A, Green K, Li X, Hayden D. Using social marketing tools to increase fuel-efficient stove adoption for conservation of the golden snub-nosed monkey, Gansu Province, China. Cons Evid. 2013;10:32-6.

50. Wibowo Novriyanto JT, Iskander W, Campbell-Smith G, Linkie M. Linking coastal community livelihoods to marie conservation in Aceh, Indonesia. Oryx. 2012;46:508-15.
51. Mijani-Rahman Md, Begum A. Implication of livelihood diversificaton on wetland resources conservation: a case from Bangladesh. J Wetlands Ecol. 2011;5:59-65.

52. Langholz J. Exploring the effects of alternative income Opportunities on rainforest use: insights from Guatemala's Maya biosphere reserve. Soc Nat Res. 1999;12:139-49.

53. Stronza A. The economic promise of ecotourism for conservation. J Ecotourism. 2012;6:210-21.

54. Nautiyal S. Can conservation and development interventions in the Indian Central Himalaya ensure environmental sustainability? A socioecological evaluation. Sust Science. 2011;6:151-67.

55. Islam MdJ, Nath TK. Forest-based betel leaf and betel nut farming of the Khasia indigenous People in Bangladesh: approach to biodiversity conservation in Lawachara National Park (LNP). J For Res. 2014;25:419-27.

56. Hill NAO, Rowcliffe JM, Koldeway HJ, Milner-Gulland EJ. The interaction between seaweed farming an alternative occupation and fisher numbers in the central Philippines. Conserv Biol. 2011;26:324-34.

57. Eastmond A, Faust B. Farmers, fires, and forests: a green alternative to shifting cultivation for conservation of the Maya forest? Landscape Urban Plan. 2008;74:267-84.

58. Schuhbauer A, Koch V. Assessment of recreational fishery in the Galapagos Marine Reserve: failures and opportunities. Fisheries Res. 2013;144:103-10.

59. Blomley T, Namara A, McNeilage A, Franks P, Rainer H, Donaldson A, Malpas R, Olupot W, Baker J, Sandbrook C, Bitariho R, Infield M. Development and gorillas? Assessing 15 years of integrated conservation and development in south-western Uganda. Natural Resources Issues No. 23, 2010. International Institute for Environment and Development. (http:// pubs.iied.org/14592IIED.html). Accessed online June 2015.

60. Herrold-Menzies M. Integrating conservation and development: what we can learn from Caohari, China. J Env Dev. 2006;15:382-406.

61. Brown L. Marine protected areas, co-management and livelihoods: Coastal change in Vietnam. PhD Thesis submitted to the University of Sydney, 2013. (http://ses.library.usyd.edu.au/handle/2123/9505). Accessed online June 2015.

62. Varma K. The asiatic Lion and the Maldharis of Gir Forest: an assessment of Indian eco-development. J Env Dev. 2009;18:154-75.

63. Brock A. Beyond fishing? the impact of microcredit on alternative livelihoods in South Sulawesi, Indonesia. Masters Project submitted to the Nicholas School of the Environment of Duke University 2013. (http:// dukespace.lib.duke.edu/dspace/bitstream/handle/10161/6822/Brock_ MastersProject.pdf?sequence=1). Accessed online June 2015.

64. Martinez-Reyes JE. Beyond nature appropriation: towards post-development conservation in the Maya Forest. Conserv Soc. 2014;12:162-74.

65. Leimu R, Koricheva J. What determines the citation frequency of ecological papers Trends in Ecology and Evolution. Trends Ecol Evol. 2005;20(1):28-32.

66. Center for Theory of Change (http://www.theoryofchange.org/ what-is-theory-of-change/.

\section{Submit your next manuscript to BioMed Central and take full advantage of:}

- Convenient online submission

- Thorough peer review

- No space constraints or color figure charges

- Immediate publication on acceptance

- Inclusion in PubMed, CAS, Scopus and Google Scholar

- Research which is freely available for redistribution 